\title{
ANÁLISE DE LINEAMENTOS NA EXPLORAÇÃO MINERAL: APLICAÇÃO NO SUDESTE PAULISTA
}

\author{
Paulo Cesar PRESSINOTTI \\ Yociteru HASUI \\ Rubens Borges da SILVA \\ Fausto Luís STEFANI \\ Maurício TRINDADE \\ Mario Otávio COSTA
}

\section{RESUMO}

Com o objetivo de selecionar áreas-alvo potencialmente favoráveis a hospedarem mineralizações de Sn e W associadas espacial e geneticamente a plutonismo ácido, levando-se em consideração a forte associação existente entre estas mineralizações e fraturamento (lato sen$s u$ ), foi realizada uma análise dos lineamentos extraídos de imagens de satélite e radar, para a região sudeste do Estado de São Paulo.

Esta análise teve por finalidade caracterizar: a) áreas intensamente fraturadas; b) áreas com padrão de fraturamento de azimute distinto dos de cunho regional; e c) feixes de fraturas de ocorrência regional. Os resultados obtidos foram integrados com dados geológicos e geofísicos, permitindo a seleção de inúmeras áreas-alvo, as quais vêm sendo objeto de levantamento geológico e geoquímico.

Como consequiência, descobriram-se novos corpos graníticos não-foliados, intrusivos, discordantes e evoluídos, bem como produtos de alteração metassomática (graisens) em áreas intensamente fraturadas e associados a esses corpos. Além disso, os estudos efetuados apontaram para o sudeste paulista um modelo de descontinuidades lineares reativadas em períodos de instabilidade tectônica.

\begin{abstract}
This paper deals with a satelite and radar imagery analysis, covering the southeastern region of the state of São Paulo, Brasil, aiming to select target areas, potentially favorable to host Sn and W mineralizations, spatially and genetically related to acid plutonism.

These mineralizations are known to be strongly associated with fracturing (lato sensu); therefore an image analysis focusing on lineaments was done to characterize: 1) intensely fractured areas; 2) areas showing fracture patterns whith azimuths distinct from the regional one; and 3) systems of aligned fractures, of regional occurrence.

The results were integrated with geological and geophysical data, allowing the selection of several target-areas, which were subject to geological and geochemical surveys.

New non-foliated, discordant, intrusive granitic bodies were discovered; metassomatic alteration products (greisens) associated with them were identified along intensely fractured areas.

The study suggests, for the southeastern region of the state of São Paulo, a model of linear discontinuities reactivated during thermo-tectonic instability periods.
\end{abstract}

\section{INTRODUÇÃO}

Dentre as escolas que norteiam a análise metalogenética regional, algumas permeiam os modelos metalogenéticos. De acordo com ROUTHIER (1980), são reconhecidas três escolas: a) Bilibiana, que considera uma evolução fixista a partir de uma faixa móvel desenvolvida numa zona de subsidência alongada ou geossinclíneo; b) Lineamentarista ou Regmatista, em que a base do pensamento se apóia na ocorrên- cia das concentrações minerais ao longo de grandes descontinuidades ou em suas intersecções (nós-mineralizados); c) a escola da Tectônica Global, com seus conceitos estabelecidos na tectônica global ou subducionista, estabelecendo relações espaciais com margens continentais ativas e zonas de subducção.

ROUTHIER (op. cit.) introduziu uma nova escola, a do Método Metálico Quantitativo, baseando-se na delimitação dos domínios metálicos, marcando o conteúdo do metal predomi- 
nante, da maneira mais simples possível e englobando os principais depósitos.

Com o advento dos sensores remotos (radar e satélite), o traçado de lineamentos, ou faixas de lineamentos, tornou-se uma prática habitual em trabalhos exploratórios, procurando definir descontinuidades estruturais mineralizadas (ou que pudessem favorecer concentrações minerais), ou ainda "nós-estruturais" mineralizados. Os grandes lineamentos representariam as principais descontinuidades estruturais que atuam como corredores de canalização e dissipação de energia. As feições geológicas a eles associadas incluem uma intensificação de intrusões, deposição, deslocamento, deformação, metamorfismo e mineralização (O’DRISCOLL, 1986).

Os trabalhos aqui efetuados não têm suas bases fixadas na escola lineamentarista, mas visam simplesmente - através do tratamento de lineamentos extraídos de imagens de sensores remotos, em interação com outros dados (geológicos, geofísicos, geoquímicos etc.) - reconhecer estruturas que possam atuar como metalotetos reveladores de mineralização. Imagens de sensores remotos se constituem em produtos adequados para a extração de lineamentos, pois proporcionam uma visualização regional das estruturas geológicas.

\section{OBJETIVO}

Este trabalho tem por objetivo apresentar alguns métodos de estudo de lineamentos extraídos de imagens de sensores remotos - os quais foram aplicados em interação com dados geológicos e geofísicos visando à seleção de áreas-alvo potencialmente favoráveis a encerrarem mineralizações de Sn e W associadas a plutonismo ácido, numa área de $32.000 \mathrm{~km}^{2}$ no Pré-Cambriano do sudeste paulista $-\mathrm{e}$ as conclusões obtidas.

\section{RELAÇÃO ENTRE PLÚTONS, FRATURAS E MINERALIZAÇÕES}

Existe uma relação muito íntima entre mineralizações de metais raros, bases, U, Be, F, $\mathrm{Ta}$, ETR etc. com plútons graníticos, fraturamento (lato sensu) e maiores descontinuidades crustais. Esta associação foi observada por diferentes pesquisadores e em diferentes escalas, como por exemplo:

a) BETTENCOURT et al. (1981) relatam que na província estanífera amazônica os granitos e as mineralizações associadas estão controlados por lineamentos antigos, próximos a margens de aulacógenos, onde estruturas do tipo horst tiveram razoável soerguimento;

b) BURNHAM \& OHMOTO, 1980 concluíram que, num processo ortomagmático, a passagem da fase transicional para a fase hidro- termal é marcada, na câmara magmática, por uma pressão interna de fluidos que pode atingir até milhares de bares enquanto que a pressão litostática é da ordem de centenas de bares, o que provoca fraturamento hidráulico;

c) ABRAMS et al. (1983) mencionaram áreas intensamente fraturadas como potenciais à exploração de cobre porfirítico;

d) o modelo de mineralização de SIMPSON et. al. (1979) para U, retomado por PLANT et al. $(1983,1988)$ para Sn e W, evidenciou que a trama de fraturamento local favorece o estabelecimento de células convectivas e processos de interação plúton-água meteórica.

Essa associação pode ser relacionada a diversas situações genéticas. Pode-se lembrar, por exemplo, que:

a) o comportamento das camadas litosféricas sob regime de tensão compressional ou extensional é distinto. Para um estado de tensão extensional os leitos litosféricos comportam-se, por um grande intervalo de espessura, como predominantemente rúpteis, enquanto que para um regime de tensão compressional somente a porção mais superior da crosta se apresenta com comportamento rúptil (NEUGEBAUER \& REUTHER, 1987). Nos regimes extensionais podemse desenvolver fraturas a profundidades consideráveis ( $40 \mathrm{~km}$ ou mais), as quais atuam como condutos à ascensão de magmas por propagação por diques (SHAW, 1980 apud CASTRO, 1987). O comportamento rúptil dos leitos litosféricos favorece o desenvolvimento de fraturamento termal e transporte de magma por dique, que prove um sistema efetivo de transporte vertical para a superfície;

b) na câmara magmática, a passagem da fase transicional para a fase hidrotermal é marcada por uma pressão interna de fluidos (BURNHAM \& OHMOTO, 1980) que pode produzir intenso fraturamento hidráulico e gerar campos de fraturamento local;

c) plútons tardios, pós-tectônicos ou anorogênicos possuem, no geral, posicionamento magmático controlado estruturalmente por descontinuidades crustais.

Áreas sujeitas ao regime de esforços referido em (a) podem ser, tentativamente, rastreadas através de intensidade de fraturamento; campos de fraturamento local provocados por fraturamento hidráulico ou outro fenômeno, através de mapas de índice de atipicalidade angular de fraturamento e/ou desvio padrão do azimute; e descontinuidades crustais, por feixes alinhados de fraturamento, que se constituem em possíveis indicadores de zonas de fraqueza crustal (ALIYEV, 1980). 


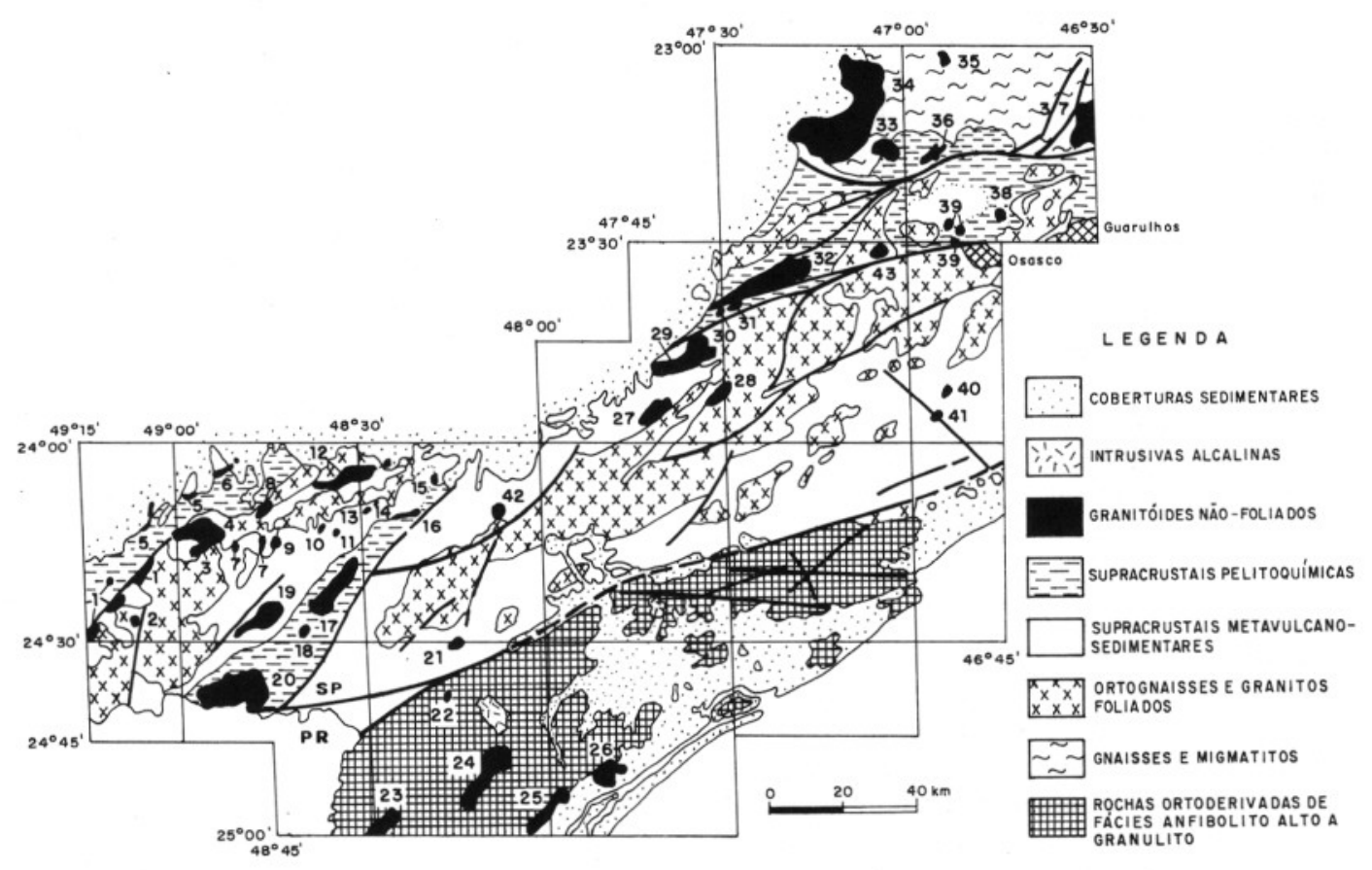

RELACÃO DOS CORPOS GRANITICOS NÄO-FOLIADOS

1. Suite Bairro do Serrinho
2. Corrego Comprido
3. Bairro dos Correos
4. Sguário
5. Campina do Veado
6. Santo Biandino
7. Capuovinho
8. Capote
9. Serro Velha
10. Sant'ano
11. Empossados
12. Capõo Bonito
13. Cravo
14. Pinhalzinho

15. Rio Abaixo
16. Freguesio Velha
17. Espírito Santo
18. Vorgem Grande
19. Apiai
20. Itodeo
21. Sem denominação
22. Barro do Braço
23. Serra do Virgem Mario
24. Guaraú
25. Mandiro
26. Serro do Paratiu
27. Córrego do Gózeo
28. Turvo

29. Pilar do Sul

30. Lavros

31. Piraporo

32. Säo Francisco

33. Bonfim

34. It

35. Morungabo

36. Terra Nova

37. Atibaic

38. Toipas

39. Itaim

40. São Lourenço

41. Vorginhe

42. Aroçoeiro

43. Mailasqui

FIGURA 1 - Panorama geológico da porção sul-sudeste do Estado de São Paulo. 


\section{ANÁLISE DE LINEAMENTOS}

\subsection{Estudo de parâmetros escalares}

Sob esta designação foram agrupados os parâmetros de freqüência e densidade de lineamentos, os quais levam em consideração somente grandezas escalares, desconsiderando o rumo (vetor) dos lineamentos em estudo.

Define-se freqüência como o número de lineamentos presentes numa cela (uma quadrícula dentro de um reticulado) unitária, e densidade como o comprimento dos lineamentos $(\mathrm{Km})$ presentes na cela. $\mathrm{O}$ estudo de tais parâmetros tem encontrado algumas objeções decorrentes do fato de serem eles influenciados por variações líticas e por diferenças de detalhamento por fotointérpretes diferentes.

A diversidade de litotipos influenciando os resultados é atributo inerente da própria Geologia e, neste contexto, deve ser analisada. Em relação a possíveis falhas introduzidas por fotointérpretes distintos sabe-se que: a) durante a extração de lineamentos cada fotointérprete identifica o mesmo trend ou direção de lineamento (Relatório Petrobrás, 1986), o que não muda com a escala de anotação do observador; b) em relação ao nível de detalhamento, é de se esperar que exista um coeficiente de proporcionalidade na extração de lineamentos por fotointérpretes distintos, de modo que os resultados obtidos, quando tratados na forma de percentil, não sejam substancialmente distintos.

\subsection{Extração dos dados}

O termo lineamento é aqui utilizado conforme definido originalmente por HOBBS (1904) e posteriormente modificado por O' LEARY et al. (1976). É aplicado a "uma feição linear, mapeável, simples ou composta, contínua ou descontínua, da superfície terrestre, cujas partes estão alinhadas num arranjo retilíneo ou suavemente curvo, que difere diretamente dos padrões que lhes são adjacentes, e, presumivelmente, reflete um fenômeno de subsuperfície".

A extração dos lineamentos com base em classificações genéticas foi preterida em virtude da necessidade de extenso suporte de campo para a sua utilização, pois estruturas iguais podem se expressar de formas distintas e, ao contrário, estruturas distintas podem ter a mesma representação na imagem.

Falhas e fraturas no terreno tendem a se comportar, de maneira geral, como feições topográficas retilíneas e negativas. A ação física e química da água nestas estruturas proporciona o aparecimento de sulcos, os quais, por vezes, se alternam com cristas retilíneas, que podem ser salientadas por silicificação ou diques intrusivos A extração de lineamentos foi efetuada visualmente em papel ultrafan, com o auxílio de uma lupa de mesa, adotando-se os baixos topográficos como critério para o posicionamento do traço do lineamento.

Neste trabalho foram utilizadas três imagens de radar P\&B do projeto Radambrasil, escala $1: 250.000$, e os lineamentos extraídos foram digitalizados numa mesa digitalizadora Digigraf (cerca de 70.000).

\subsection{Tratamento dos dados}

Num reticulado de $3 \times 3 \mathrm{~km}$ com recobrimento lateral de $50 \%$, foram calculadas e plotadas no centro de cada cela a freqüência e a densidade dos lineamentos ali encontrados. Esses valores foram assumidos como reflexo da intensidade de fraturamento na cela.

Para a definição das áreas anômalas, ou se$\mathrm{ja}$, das áreas mais intensamente fraturadas, adotou-se o seguinte procedimento:

a) foram considerados individualmente os mapas de freqüência e densidade de lineamentos obtidos a partir de cada mosaico de radar;

b) construiu-se um histograma acumulativo do parâmetro analisado pela sua classe. Neste histograma também consta a porcentagem acumulada (100\%), presente na FIGURA 2a, b;

c) para a definição dos valores de freqüência ou densidade que passariam a representar as áreas mais intensamente fraturadas adotaram-se aqueles situados acima da porcentagem acumulada de $84 \%$;

d) para cada imagem estudada, foram elaborados os mapas de freqüência e densidade anômalos.

\subsection{Estudo dos parâmetros vetoriais}

Sob esta denominação consideraram-se os parâmetros de índice de atipicalidade angular de lineamentos (IAAL) e do desvio padrão do azimute (DPA), os quais levam em consideração, no tratamento estatístico, o azimute do lineamento.

\subsection{1 Índice de atipicalidade angular de linea-} mentos (IAAL)

PRETORIUS \& PARTRIDGE (1974) utilizaram este índice, quando em fase de prospecção regional, como um critério auxiliar para a identificação de áreas onde pudessem ser encontrados corpos ígneos, tendo-se como estratégia a detecção de campos de fraturamento local. $\mathrm{O}$ método consiste na identificação das áreas que apresentem uma maior densidade de lineamen- 

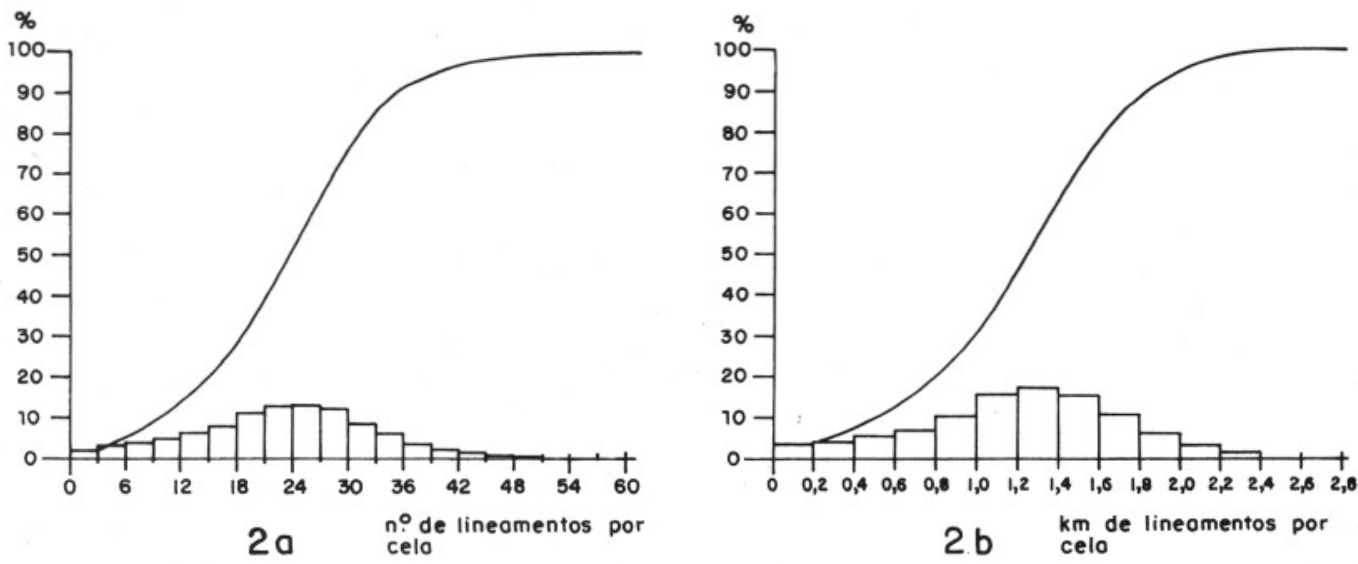

FIGURA 2a - Freqüência de lineamentos em porcentagem; $2 b-$ densidade de lineamentos em porcentagem.

$\sum D 0$

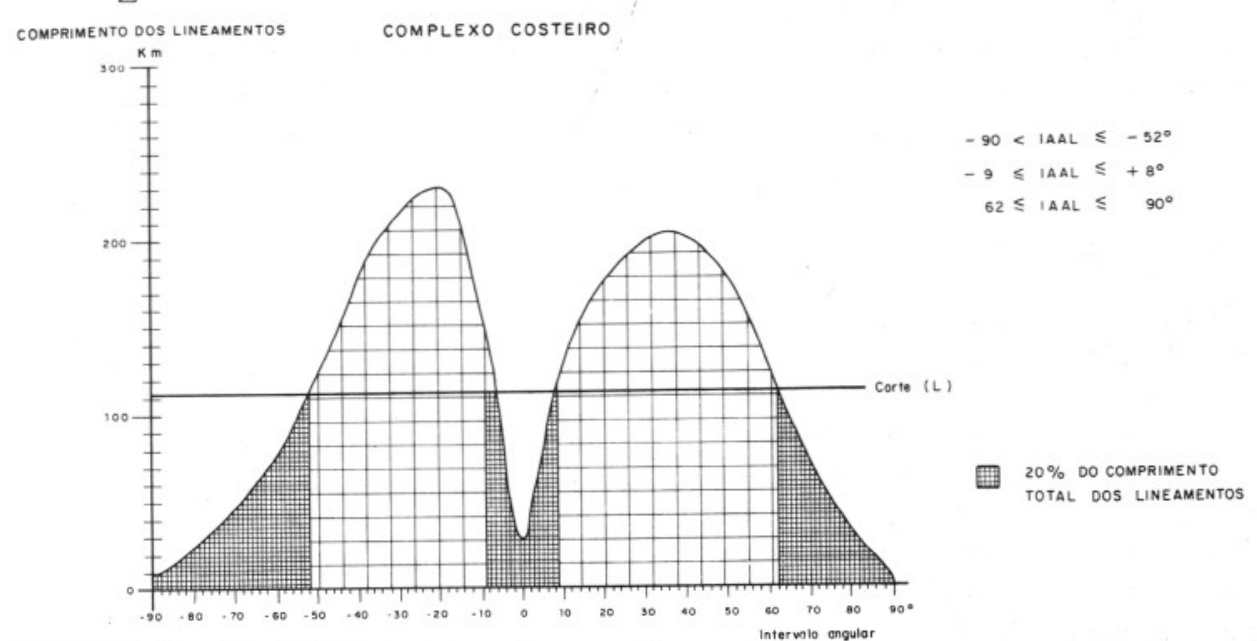

FIGURA 3 - Definição de intervalos angulares atípicos.
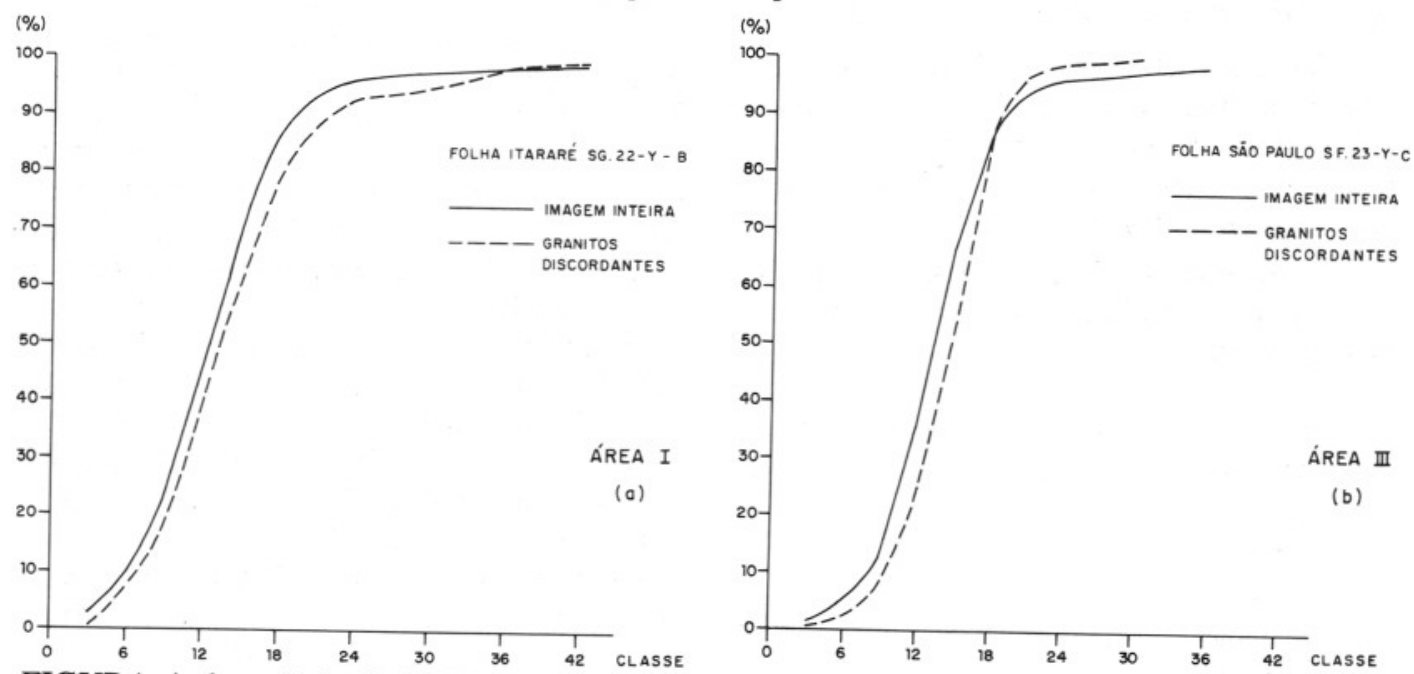

FIGURA 4a,b - Relação DPA, quadrante NW, imagem inteira $\times$ granitos discordantes. 
DISTRIBUICÃO DO DPA

IMAGEM SG. 22- $X-B$

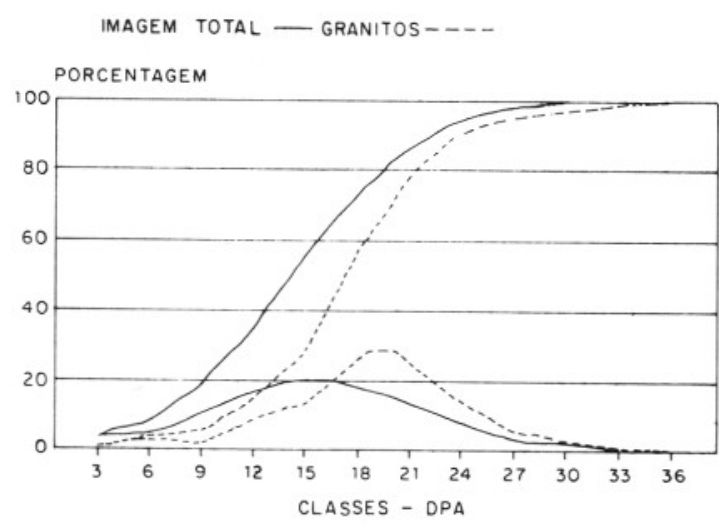

Ganitos considerodos: Squórị, Capỏo Bonito, Itooco, Guerou, Boirro dos Cosreics, Serro do Virgem Mario

FIGURA 5 - Relação DPA, quadrante NE, imagem inteira $\mathrm{x}$ granitos discordantes.

tos com azimutes distintos daqueles do padrão regional. Nesse estudo, aqueles autores consideraram compartimentos geológicos com carac- terísticas semelhantes, tais como: grau metamórfico, estilo deformacional, idade, litotipos, nível de erosão etc.

Na região em estudo, esta compartimentação foi feita de acordo com as principais unidades litoestratigráficas que ocorrem no Vale do Ribeira. Em cada um desses compartimentos, fez-se um histograma de barras lançando-se no eixo das abcissas o azimute dos lineamentos em intervalos angulares $2^{\circ}$, e no eixo das ordenadas a soma do comprimento dos lineamentos existentes naquele intervalo angular. Nestes histogramas podem ser observadas cristas, que denotam os intervalos angulares típicos de lineamentos, e depressões, que denotam os intervalos angulares atípicos.

Para a delimitação dos intervalos angulares típicos ou atípicos fez-se, nos histogramas, um corte $\mathrm{L}$ paralelo ao eixo da abcissa, de modo que na área situada sob a curva conste $20 \%$ do comprimento total dos lineamentos medidos. A Figura 3 exemplifica este procedimento para um dado compartimento.

$O$ índice de atipicalidade angular de lineamentos (IAAL) é dado pela equação:

$$
\text { IAAL }=\frac{\text { densidade dos lineamentos com intervalos angulares atípicos }}{\text { densidade de todos os lineamentos }}
$$

\section{Obrigatoriamente, $\theta \leq$ IAAL $\leq 1$}

Num reticulado de $3 \times 3 \mathrm{~km}$, com recobrimento lateral de $50 \%$, foi calculado e plotado no centro de cada cela o valor do IAAL obtido. Para a definição dos valores de IAAL anômalos e possíveis de representarem campos de fraturamento local, construiu-se um histograma por classe de atipicalidade $\mathrm{x}$ freqüência acumulada (\%) e consideraram-se aqueles situados acima da porcentagem acumulada de $84 \%$.

\subsubsection{Desvio padrão do azimute (DPA)}

Este parâmetro reflete a dispersão azimutal dos lineamentos, e, em tese, a análise dos mapas de contorno de isovalores do desvio padrão do azimute (DPA) permite a detecção de possíveis campos de fraturamento local.

O cálculo dos DPA efetivou-se em celas de $3 \times 3 \mathrm{~km}$ com recobrimento lateral de $50 \%$. O azimute médio é dado por:

$\overline{\mathrm{x}}=\sum_{\mathrm{i}=1}^{\mathrm{n}} \frac{\mathrm{xi}}{\mathrm{n}}$, onde: $\begin{aligned} \mathrm{x} & =\text { azimute médio } \\ \mathrm{xi} & =\text { azimute do traço } \mathrm{i}\end{aligned}$

e seu desvio,

$$
\mathrm{SD}=\sqrt{\sum_{\mathrm{i}=1}^{\mathrm{n}} \frac{(\mathrm{xi}-\mathrm{x})^{2}}{\mathrm{n}-1}}
$$

onde: $\mathrm{SD}=$ desvio padrão

$\mathrm{x}=$ azimute médio

$\mathrm{xi}=$ azimute do traço $\mathrm{i}$

Conforme apresentado na Figura 3, existem duas modas de azimutes de lineamentos, de direções NW e NE. Assim, para o estudo desse parâmetro, consideraram-se separadamente os lineamentos contidos em cada quadrante.

De modo análogo aos estudos anteriores, 0 cálculo do DPA foi feito em celas de $3 \times 3 \mathrm{~km}$, com recobrimento lateral de $50 \%$.

Para verificar a validade deste estudo, fezse uma comparação dos índices de DPA obtidos numa imagem inteira com alguns granitos nãofoliados de feições claramente discordantes.

a) em relação ao quadrante NW, constatouse que não existe uma assinatura distinta entre os índices de DPA referentes à imagem inteira e os granitos tomados com referência (Figura $4 a, b$ );

b) em relação ao quadrante NE, foi constatada uma assinatura distinta entre os índices de DPA relacionados com a imagem inteira e os granitos de referência, com uma ligeira tendência de índices mais altos relacionados aos granitos (Figura 5).

Em face desses resultados, trabalhou-se somente com o quadrante NE. Em relação ao quadrante NW, supõe-se que o fraturamento marcante do Mesozóico (NW) deu-se indistintamente sobre os granitos e encaixantes, mascarando as relações procuradas neste tipo de estudo. 


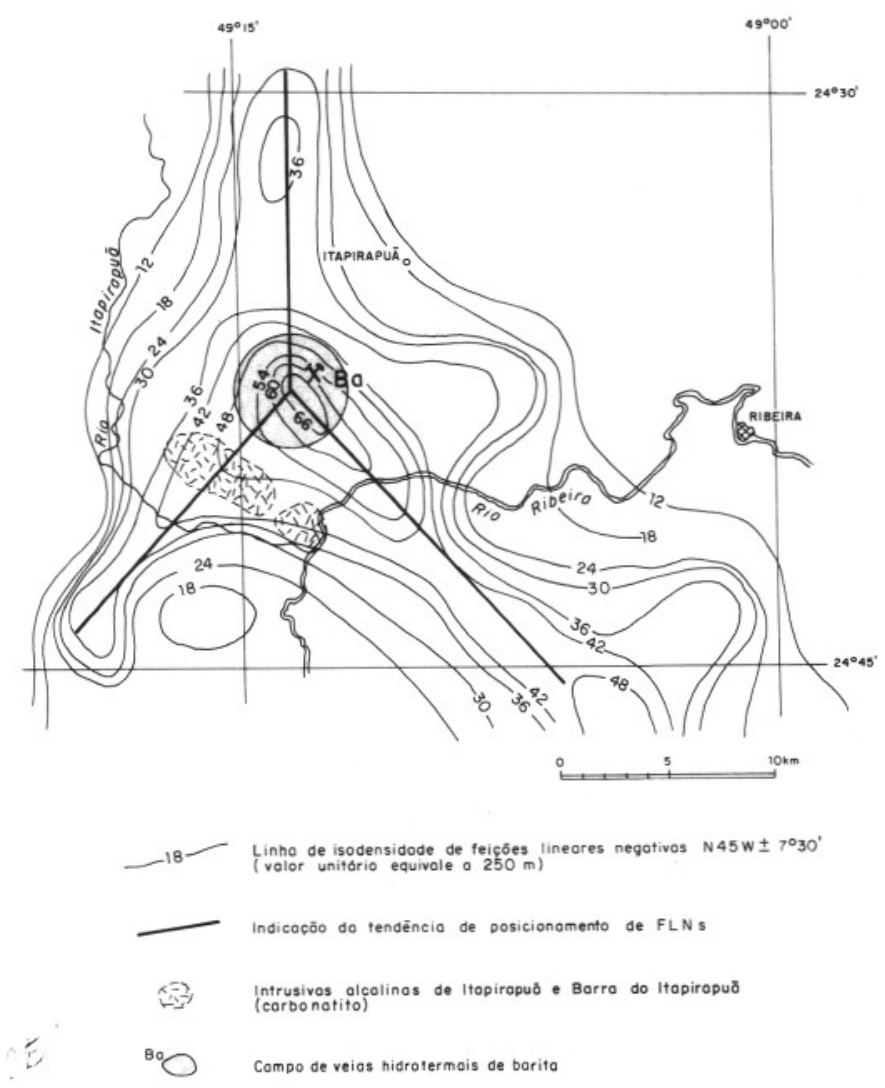

FIGURA 6 - Mapa de isodensidade de feições lineares negativas N45W.
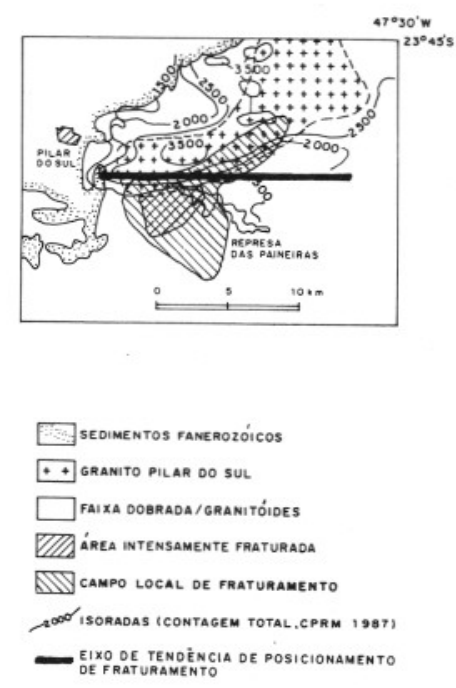

FIGURA 7 - Critérios regionais de avaliação do granito Pilar do Sul.

Para a definição dos valores com DPA anômalos, consideraram-se os valores situados acima da porcentagem acumulada de $84 \%$ no histograma de porcentagem acumulada por classe de DPA.

\section{ANÁLISE REGIONAL DO FRATURAMENTO}

ALIYEV (1980) propôs que zonas de fraqueza ocultas na crosta terrestre poderiam ser identificadas através da análise estatística de fraturamento. Sob o termo fratura, agrupou os lineamentos presentes. No traçado destas feições foram utilizadas imagens de satélite, escala 1:500.000. A metodologia por ele proposta consiste, basicamente, em: a) extração de todos os lineamentos; b) identificação dos que ocorrem na forma de feixes com trend definido; c) para cada feixe detectado, o traçado de linhas de isodensidade.

De acordo com ALIYEV (op. cit.), o traçado dessas linhas revela que os lineamentos se posicionam no terreno segundo faixas alongadas, as quais não necessariamente coincidem com o trend do feixe definido. Estas faixas, onde se concentram preferencialmente os lineamentos, foram consideradas como zonas de fraqueza da crosta.

\subsection{Trabalhos realizados}

A extração dos lineamentos se efetuou, rigorosamente, para elementos texturais retilíneos e negativos (ou feições lineares negativas FLNs), do mesmo tamanho, tais como identifi- 


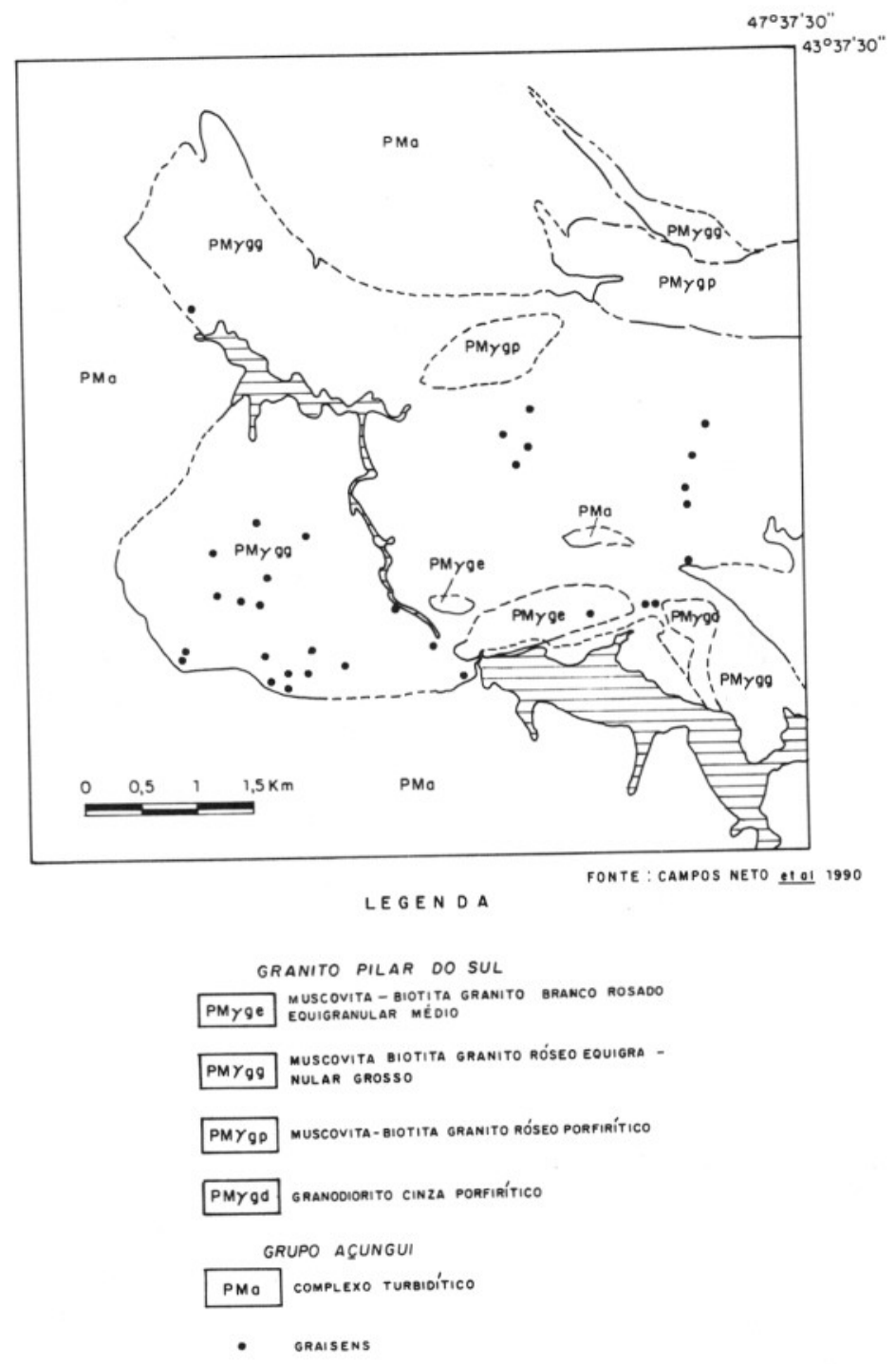

FIGURA 8 - Mapa geológico da porção oeste do granito Pilar do Sul.

cados na imagem. Neste trabalho foram utilizadas seis imagens de satélite LANDSAT TM 5, na escala 1:250.000 e extraídas aproximadamente 87.000 FLNs.

Em papel ultrafan, sobre os mapas de lineamentos, fez-se um reticulado de 3' x 3'. No centro de cada cela, para cada feixe de FLNs definido, considerando-se uma variação angular de $7,5^{\circ}$, calculou-se e plotou-se no centro de cada cela sua densidade, e posteriormente fez-se o traçado das linhas de isovalor.

Conforme o enunciado por ALIYEV (op. cit.), foi constatado que os lineamentos se posicionam no terreno segundo faixas ligeiramente retilíneas e alongadas que, por sua vez, não correspondem necessariamente à direção de FLN considerada.

\section{RESULTADOS OBTIDOS}

$\mathrm{O}$ tratamento de lineamentos gerou vários mapas que foram integrados com dados geológi- cos, geofísicos, morfoestruturais, mineralizações etc., permitindo a constatação de associações entre mineralizações e os estudos efetuados e, por analogia, reconhecer áreas-alvo para investigações posteriores. Assim, através da exemplificação de alguns casos estudados, pretende-se mostrar a utilidade da análise estatística de lineamentos aplicada à exploração mineral.

a) a Figura 6 mostra, a sudoeste da localidade de Itapirapuã, um "nó” de eixos də máxima densidade FLNs de direção $\mathrm{N} 45^{\circ} \mathrm{W}$, as intrusivas alcalinas Mesozóicas de Itapirapuã e de Barra de Itapirapuã (carbonatitos) e um campo de veios hidrotermais de barita, onde alguns desses veios estão encaixados em injeções alcalinas ultrabásicas (PRESSINOTTI \& SILVA, 1988). A direção de fraturamento NW mesozóica é bem conhecida no Arco de Ponta Grossa pelos enxames de diques de diabásio aí intrudidos. Naturalmente, outros pontos onde foram constatadas concentrações de FLNs 


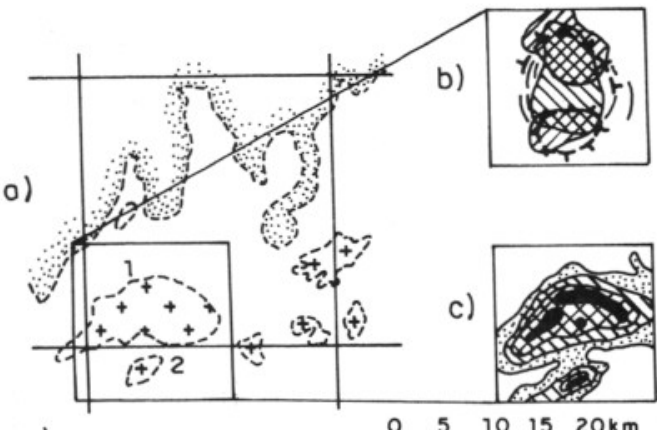

o)

ㅇ $5 \quad 10 \quad 15 \quad 20 \mathrm{~km}$

SEDIMENTOS FANEROZÓICOS

† t. GRANITOS NĀO-FOL̨IADOS

1. GRANITO SGUARIO

2- GRANITO BAIRRO DOS CORREIAS

$\square$ TERRENOS GRANITO-GNÁISSICOS, SUPRACRUS TAIS METAVULCANO SEDIMENTARES

b)

NW ÁREAS INTENSAMENTE FRATURADAS

WIA ÁREAS COM AZIMUTE ATÍPICO DE FRATURAMENTO

MORFOESTRUTURA DELIMITADA POR ASSIME

y TRIA DE DRENAGEM

LINEAMENTOS ESTRUTURAIS FOTOINTERPRE-

(i) TADOS

c)

RADIOMETRIA (CPRM -1987)

Q $>3500 \mathrm{cPs}$

एख 2500 o $3500 \mathrm{cps}$

WV $2000 \circ 2500 \mathrm{cps}$

W. 1500 o $2000 \mathrm{cps}$

$\square<1500 \mathrm{cps}$

FIGURA 9-Critérios de avaliação dos granitos Squário e Bairro dos Correios.

de direção $\mathrm{N} 45^{\circ} \mathrm{W}$, com eixos de máxima densidade FLNs se interceptando tal qual padrão apresentado na Figura 6, constituem-se, por analogia, em áreas-alvo para investigações de possíveis intrusões alcalinas aflorantes ou subaflorantes.

b) a Figura 7 mostra que a porção sudoeste do granito Pilar do Sul (STEIN, 1984), póstectônico, circunscrito e discordante em seqüências metassedimentares, é marcada por uma zona intensamente fraturada (freqüência $e$ densidade de lineamentos) e, no seu extremo oeste, foram detectados índices anômalos de DPA e IAAL. Ainda apresenta aerorradiometria (contagem total) anômala (CPRM, 1987). Essas feições em granito pós-tectônico definem área-alvo para investigações de mineralizações epigenéticas.

Com base nestes critérios foi efetuado um reconhecimento geológico no granito Pilar do Sul, sendo constatados inúmeros veios de endo e exograisens localizados notadamente na sua porção oeste, onde o corpo é nitidamente discordante nos metassedimentos encaixantes. Análi- se química de endograisen revelou teores de 590 ppm de $\mathrm{Sn}, 1.212 \mathrm{ppm}$ de $\mathrm{Li}, 11,8 \%$ de $\mathrm{K}_{2} \mathrm{O}$, 42 ppm de W, 22 ppm de Be e 0,92\% de F. Esses teores são compatíveis com os topázios micagraisens mineralizados em Sn e W do granito Correas (GORAIEB et al., 1988), ao qual se encontra associada a principal mineralização de $\mathrm{Sn}$ e W do sudeste paulista.

O granito Pilar do Sul vem sendo avaliado quanto ao seu potencial metálico pelo IPT (1991), e também foi mapeado parcialmente por CAMPOS NETO et al. (1990), sendo assinalados inúmeros corpos de graisens filonianos, concentrados, mais notadamente, na porção SW do granito (Figura 8), onde foram detectados área intensamente fraturada e campos locais de fratura nos estudos ora realizados. Naturalmente, a existência ou não de um depósito mineral depende de vários outros fatores (sítio deposicional adequado, disponibilidade de metal, complexador, nível de erosão etc.), que são avaliados numa escala de observação local, com critérios distintos destes que são aplicados na análise regional e distrital, durante a seleção de áreas-alvo;

c) a Figura 9 mostra que as áreas de afloramento dos granitos Correas, Sguário (CPRM, 1986) e encaixantes foram detectadas como anômalas, apresentando alto grau de fraturamento, alto grau de fraturamento com azimute distinto daqueles do padrão regional e anomalia radiométrica positiva. Encontra-se associado ao granito Correas o principal depósito de Sn e W descoberto até o momento no Estado de São Paulo. A mineralização, predominantemente primária, ocorre em topázio graisens, numa área ligeiramente ovalada ( $100 \mathrm{~m}$ no eixo maior), situado num embasamento xistoso, a aproximadamente $200 \mathrm{~m}$ de cúpula albítica aflorante a nordeste do corpo granítico. O enxame de veios que ocorre na área é indicativo de que a estrutura se constitui num mega-stockwork. Naturalmente, a associação alto grau de fraturamento, campos de fraturamento local (DPA anômalo) e anomalia radiométrica são dados que se somam na indicação da existência de possíveis plútons graníticos intrusivos e evoluídos e que podem ser rastreados a nível regional;

d) o estudo de freqüência e densidade de lineamentos mostrou que as bordas da Bacia do Paraná são marcadas por alto grau de fraturamento (lato sensu); assim como existe uma tendência de posicionamento do fraturamento limitando suas bordas. De maneira geral, constata-se, no Estado de São Paulo, uma concentração de granitos não-foliados e evoluídos nas bordas da Bacia, com alguns deles de caráter alcalino - e.g. granitos São Francisco (GO- 

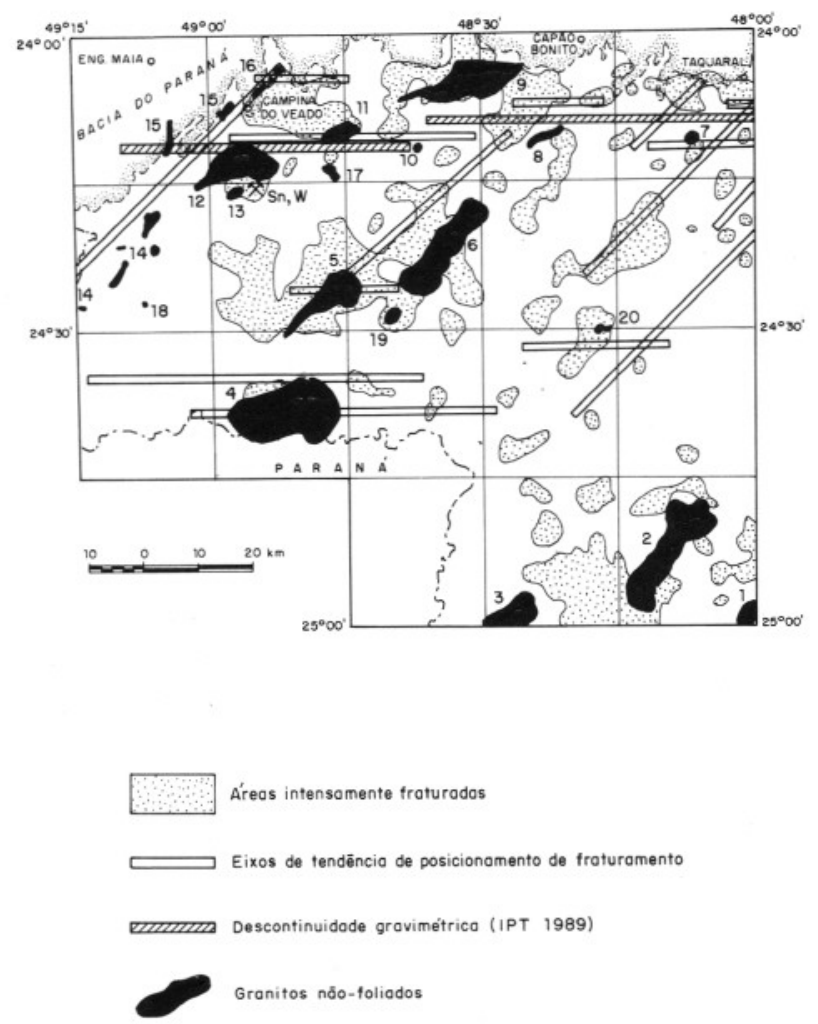

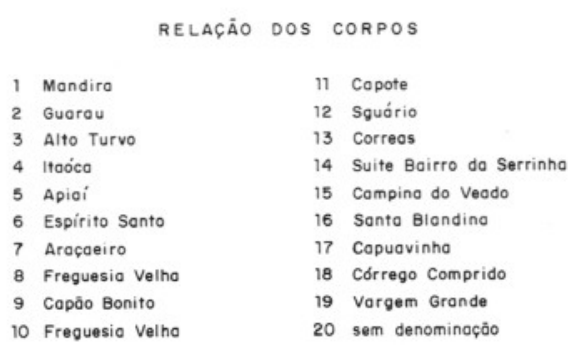

FIGURA 10 - Relação entre áreas intensamente fraturadas, eixos de tendência de posicionamento de fraturamento e granitos não-foliados.

DOY, 1990), Itu (PASCHOALATTI et al., 1987), Sguário e Campina do Veado (CPRM, 1986). Os granitos aflorantes, entre as localidades de Taquaral e Campina do Veado, associamse a importante descontinuidade gravimétrica (IPT, 1989), observada na Figura 10.

Tal situação é fortemente sugestiva de que a atual hinge line da Bacia do Paraná esteve submetida a processos de reativação ligada a hot spot que poderiam ter favorecido o estabelecimento da $\mathrm{Ba}-$ cia ao longo de calhas tafrogênicas, conforme sugerido por FÚLFARO et al. (1982). Neste contexto, as bordas da Bacia do Paraná passam a apresentar um potencial geotectônico metalogenético bastante favorável para encerrar mineralizações de metais raros associados a granitóides; e

e) o mapa gravimétrico do Estado de São Paulo (IPT, 1987) mostra que, passando ao norte de Itanhaém (SP), ocorre uma importante desconti- nuidade gravimétrica de direção $\mathrm{E}-\mathrm{W}$, de amplitude em torno de 60 mgal, e gradiente de 1 a 2 $\mathrm{mgal} / \mathrm{km}$, que se estende para W delimitando a borda da Bacia do Paraná entre as localidades de Taquaral e Campina do Veado. Os eixos E-W de tendência de posicionamento de FLNs coincidem com o traço axial desta anomalia gravimétrica de magnitude crustal (Figuras 10 e 11), permitindo também inferir, através daquela metodologia, a ocorrência desta importante descontinuidade. Nota-se ainda na Figura 11 que o posicionamento magmático da intrusiva alcalina de Juquiá ocorre num "nó" de eixos de tendência de posicionamento de FLNs, sugerindo um controle de alojamento magmático por descontinuidades.

Os trabalhos efetuados permitiram também o descobrimento de alguns corpos graníticos, de características pós-tectônicas, circunscritos e discordantes, sendo aqui apresentados os critérios, 


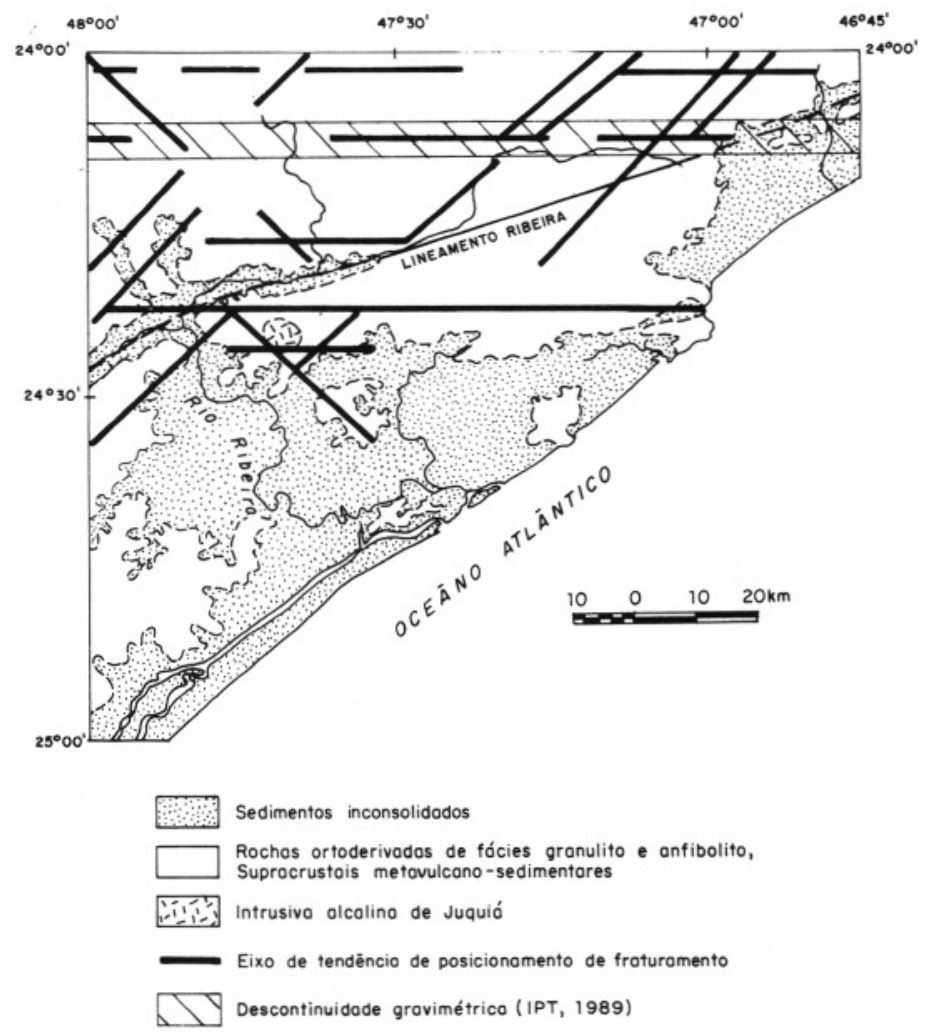

FIGURA 11 - Relação entre fraturamento, descontinuidade gravimétrica e o posicionamento magmático da intrusiva alcalina de Juquiá.

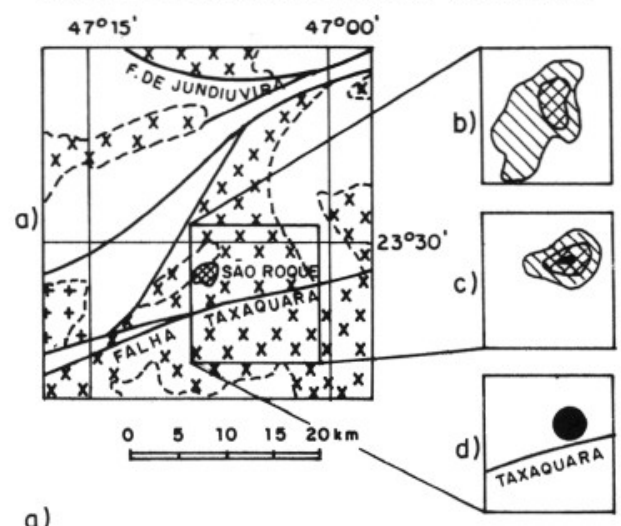

a)

++ GRANITOS NĀO FOLIADOS

X $X$ GRANITOS FOLIADOS

CASRACRUSTAIS METASSEDIMENTARES E METAVULCĀN!

b)

Q1 ÁREA INTENSAMENTE FRATURADA

Q Área com azimute de FratURAMENTO aPítico

c) BASE GEOFÍSICA: CPRM 1987

D $>3500 \mathrm{CPS}$

2500-3500 CPS

DIV 2000-2500 cPS

d)

- granito mailasoui

FIGURA 12 - Critérios de rastreamento do granito Mailasqui.

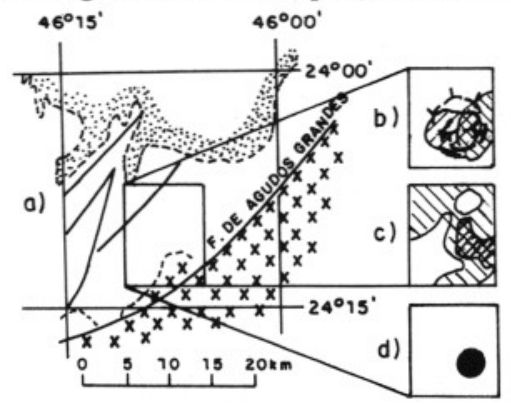

a)

SEDIMENTO FANEROZÓICOS

区邓 COMPLEXO GRANITICO DE AGUDOS GRANDES

$\square$ SUPRACRUS TAIS METASSEDIMENTARES

b)

27A ÁREA COM AZIMUTE ATÍPICO DE FRATURAMENTO

MV ÁREA INTENSAMENTE FRATURADA

Y. MORFOESTRUTURA DELIMITADA POR ASSIMETRI YY A DE DRENAGEM (1) LINEAMENTOS ESTRUTURAIS FOTOINTERPRE-

c) RADIOMETRIA (CPRM, 1987)

- > $2000 \mathrm{CPS}$

1500 A 2000 CPS

SIV 1000 A 1500 CPS

$<1000 \mathrm{cPS}$

d)

- gRANITO ARAÇAEIRO

FIGURA 13 - Critérios de rastreamento do granito Araçaeiro. 
enfocando a análise de lineamentos, que permitiram o descobrimento de dois desses corpos.

A Figura 12 mostra, na área do batólito granítico de São Roque, uma porção intensamente fraturada e com fraturamento de azimute atípico. Estes dados, somados a outros de fotointerpretação em imagens de satélite, radiométricos e morfoestruturais, permitiram a descoberta de um turmalina-granito porfirítico, de granulação fina a média, estrutura maciça ou localmente fraca orientação. Apresenta composição modal 3b, sendo identificada a schorlita (turmalina preta) como um constituinte magmático primário, chegando a apresentar, em determinadas porções, volume modal superior a $3 \%$. Suas características mineralógicas, petrográficas e químicas apontaram tratar-se de um leucogranito peraluminoso, à semelhança dos granitos de fonte crustal alojados em níveis elevados (Granito Mailasqui - Nova Descoberta de TurmalinaGranito, PRESSINOTTI et al., em preparação).

A Figura 13 apresenta, de forma análoga, a presença de área intensamente fraturada, com fraturamento de azimute atípico e cujos dados radiométricos, fotointerpretativos e morfoestruturais se somavam na indicação de corpo granítico evoluído. Os trabalhos aí realizados permitiram a descoberta de um biotita-granito $3 \mathrm{~b}$, nãofoliado, intrusivo, circunscrito e discordante em seqüências pelíticas (Granito Araçaeiro, PRESSINOTTI et al., em preparação). Estudos petrográficos constataram processos incipientes de albitização e graisenização, chegando a desenvolver localmente metassomatitos com 20 a $25 \%$ de palhetas de mica cinza, com teor de $186 \mathrm{ppm}$ de Sn e 1.400 ppm de F.

Levantamento geoquímico por sedimento de corrente indicou anomalia geoquímica para a seguinte assembléia de elementos no Granito Araçaeiro: F, Be, La, B, Li, Y. Em concentrados de bateia de sedimentos ativos de corrente, detectaram-se xenotima, monazita, topázio e tra- ços de cassiterita, que se constituem em minerais indicadores de que processos mineralizantes ali ocorreram.

\section{CONCLUSÕES}

Com os exemplos citados procurou-se demonstrar:

1) a utilidade dos métodos estatísticos de análise de lineamentos, quer seja: na identificação de áreas intensamente fraturadas, detecção de campos locais de fraturamento, identificação de descontinuidades crustais, ou como critérios adicionais na exploração de plútons graníticos, aflorantes ou subaflorantes (e.g. granitos Araçaeiro e Mailasqui); e

2) a associação existente entre produtos de alteração metassomática com granitos nãofoliados (e.g. Bairro dos Correas, Pilar doSul, Mailasqui e Araçaeiro), campos de fraturamento local e áreas intensamente fraturadas, evidenciando a importância da trama de fraturamento bem desenvolvida, em processos de alteração metassomática envolvendo plúton granítico intrusivo e rocha encaixante.

Adicionalmente, a análise do fraturamento permitiu, segundo o método de ALIYEV (1980), reconhecer faixas preferenciais de fraturamento, como nas bordas da Bacia do Paraná, que coincidem com importante descontinuidade gravimétrica, onde foi identificada uma intensificação de intrusões graníticas, com alguns corpos apresentando características de granitos tipo A, o que sugere, para ao menos parte do sudeste paulista, um modelo de descontinuidades lineares reativadas em períodos de instabilidade tectônica.

\section{AGRADECIMENTOS}

Os autores são gratos ao colega Mário Lincoln De Carlos Etchebehere pela leitura, crítica e sugestões apresentadas, e à seção de desenho da DGRM-IPT, aos desenhistas Mirna Mangini Feracini e Jaime Vergílio.

\section{REFERÊNCIAS BIBLIOGRÁFICAS}

ABRAMS, M.J.; BROWN, D.; LEPLEY, L.; SADOWSKY, R. 1983. Remote sensing for porphyry copper deposits in Southern Arizona. Econ. Geol. 7:591-604.

ALIYEV, A. 1980. Regional fracturing of the Pamirs and its mettalogenic significance. Doklady Akad., Moscow. Nauk. SSSR, 250:90-93.

BETTENCOURT, J.S.; DAMASCENO, E. C.; FRANCO, J. R. M.; FONTANELLI, W. S.; PEREIRA, N. M. 1981. Brasilian tin deposits and potential. In: INTERNATIONAL WORLD CONFERENCEON TIN, 5, 1981, Kuala Lampur, Malasia. Paper... Kuala Lampur p. 1-69.
BURNHAM, C. W.; OHMOTO, H. 1980. Late stage processes of felsic magmatism. In: GRANITIC MAGMATISM AND RELATED MINERALIZATION. Mining Geology Special Issue, n. 8, p. 1-12.

CAMPOS NETO, M. DA C.; BERGMANN, M.; JUNIOR, O. S.; FIGUEIREDO, M. C. H. 1990. Geologia da Folha Pilar do Sul, escala 1:25.000. São Paulo, USP. SCTDE/PRÓ-MINÉRIO. 96p. il.

CASTRO, A. 1987. On granitoid emplacement and related structures. A review. Geologische Rundschau, Stuttgart, 76(1):101-124. 
CPRM-COMPANHIA DE PESQUISAS DE RECURSOS MINERAIS. 1986. Projeto Engenheiro Maia e Ribeirão Branco. São Paulo, PRÓ-MINÉRIO/CPRM (Rel. Final) 1987. Projeto São Paulo-Rio de

Janeiro, mapas de contorno radiométrico (contagem total), escala 1:250.000. Rio de Janeiro, Conv. DNPM/CPRM.

CREPANI, E. 1987 Análise de fraturas através de imagens fotográficas de baixa resolução espacial: uma contribuição ao estudo da evolução da tectônica da região da chapada do Araripe - NE do Brasil. (Tese de Doutorado IGc-USP) $139 \mathrm{p}$.

FÚLFARO, V. J.: SAAD, A. R.: SANTOS, M. V. dos; VIANNA, R. B. 1982. Compartimentação e evolução tectônica da Bacia do Paraná. Rev. Bras. Geoc., 12(4):590-610.

GODOY, A. M. 1990. Caracterização faciológica, petrográfica e geoquímica dos Maciços Sorocaba e São Francisco-SP. São Paulo. (Tese de Doutoramento, IGc-USP). 220p.

GORAIEB, L. C.; OLIVEIRA, M. C. B.; MELLO, I. S. V.; SILVA, R. B. 1988. As mineralizações estano-tungsteníferas do granito Correas. In: CONGRESSO LATINOAMERICANO DE GEOLOGIA, 7, BELÉM, 1988, Belém. Anais... Belém, SBG. v. 1. p. 154-172.

HOBBS, W. H. 1904. Lineaments of the atlantic border region. Geol. Soc. Americ. Bull. 15:483-506.

IPT-INSTITUTO DE PESQUISAS TECNOLÓGICAS DO ESTADO DE SÃO PAULO. 1987. Carta gravimétrica do Estado de São Paulo, fase B. São Paulo, DMGA/IPT (Rel. 25.371)

1991. Avaliação da potencialidade mineral da área de Pilar do Sul. São Paulo. DGRM/IPT. (Rel. 28.878).

PETROBRÁS. 1986. Análise estrutural e tectônica do pré-cambriano adjacente às bacias de Barreirinhas e do Ceará através de dados de sensores remotos. 99 p. Coord. LIU, C. C.; RODRIGUES J., E. (Relatório PETROBRÁS/CENPES 673-8.984).

NEUGEBAUER, H.J.; REUTHER, C. 1987, Intrusion of igneous rocks - physical aspects - Geol. Rund, Stuttgart. 76(1):89-99.

O'DRISCOLL, E. T. S. 1986. Observations of the lineaments - ore relations. Phil. Trans. R. London. (317)A:195-218.
O'LEARY, D. H.; FRIEDMAN, J. D.; POHN, H. A. 1976. Lineament, linear, lineation: some proposed new standards for old terms. Geol. Soc. Am. Bull, v. 87, n. 10, p. 1463-1469.

PASCHOALATI, E. M., VLACH, S. R. de., AMARAL, G. 1987. Contribuição ao conhecimento da suíte intrusiva de Itu. In: SIMPÓSIO REGIONAL DE GEOLOGIA, 6, 1987, Rio Claro. Atas... Rio Claro: SBG. v. 1 , p. $47-62$.

PLANT, J. A.; SIMPSON, P. R.; GREEN, P. M.; WATSON, J. V.; FOWLER, M. B. 1983. Metalliferous and mineralized caledonian granites in relation to regional metamorphism and fracture systems in Northern Scotland. Trans. Inst. Min. Metall. B-89, p. B-33-42.

PLANT, J. A.; HALE, M.; RIDGWAY, J. 1988. Developments in regional geochemistry for mineral exploration. Trans. Inst. Min. Metall. B-97, p. B-116-140.

PRESSINOTTI, P. C.; SILVA, R. B. da. 1988. Contribuição ao estudo das mineralizações de barita da região do Xaxim, Vale do Ribeira (SP). In: CONGR. BRAS. GEOL., 35, Belém, 1988. Anais..., Belém, SBG. v. 1 p. $319-328$.

Granito Araçaeiro - nova descoberta de corpo granítico especializado em metais raros no Estado de São Paulo (em preparação).

PRESSINOTTI, P.C.; MARTINS A.F.G.; SILVA, R. B. da. Granito Mailasqui - nova descoberta de turmalina-granito no Estado de São Paulo (em preparação).

PRETORIUS, J. P. G. \& PARTRIDGE, T. C. 1974. The analysis of angular atypicality of lineaments as an aid to mineral exploration. J. South Afr. Inst. Min. Met., (10):367-369.

ROUTHIER, P. 1980. Où sont les metaux pour l'avenir? Les provinces métalliques, essai de métallogenic globale. França. BRGM: (Mémoir, 105). 400p.

SIMPSON, P. R.; BROWN, G. C.; PLANT, J. OSTLE; D. 1979. Uranium mineralization and granite magmatism in the British Isles. Phil Trans. R. Soc Lond., 291A, p. 133-160. STEIN, D. P. 1984. Esboço da evolução geológica Pré-Cambriana da Folha Pilar do Sul, $S P$. $S P-S F-23-Y-C-I V$. São Paulo, 148p. (Dissertação de Mestrado, IGc-USP.).

Endereço dos autores:

- Paulo César Pressinotti, Rubens Borges da Silva, Fausto Luis Stefani, Maurício Trindade e Mário Otávio Costa Instituto de Pesquisas Tecnológicas do Estado de São Paulo S/A - IPT - Cidade Universitária Armando Salles Oliveira - Butantã - Caixa Postal 7141 - 05508-901 - São Paulo, SP - Brasil.

- Yociteru Hasui - Instituto de Geociências e Ciências Exatas da Universidade Estadual Paulista - Campus de Rio Claro - Caixa Postal 178 - 13500-970 - Rio Claro, SP - Brasil. 